\title{
El discurso sobre la música popular contemporánea: crítica artística y divulgación periodística
}

\author{
The discourse on contemporary popular music: arts criticism \\ and journalistic popularization
}

\author{
ANTONI MAESTRE BROTONS \\ UNIVERSITAT D'ALACANT
}

Enviado: $15 / 02 / 2014$

Aceptado: 20/03/2014

\begin{abstract}
The cultural meaning of music is produced by musicians, critics, musicologists, audience, and record industry. According to Pierre Bourdieu, this meaning is related to the symbolic value of music as a field where social fights take place to raise cultural capital. Specifically, the discourse on contemporary popular music, as shown in newspaper articles, is based upon some features that run counter to classical music: corporeality, emotion, and femininity. Thus the articles are full of metaphors on irrationality and energy. Although those values were once subversive -they actually resisted highbrow culture-, jazz or rock have been assimilated while at the same time other music styles such as dance or pop have been relegated because of their commerciality and unintelligence.
\end{abstract}

Keywords: rock, pop, criticism, discourse, mass culture.

RESUMEN: El significado de la música es cultural y se elabora mediante un discurso en el que intervienen autores, críticos, musicólogos, público y discográficas. De acuerdo con Pierre Bourdieu, este significado se debe al valor simbólico atribuido a la música como campo en el que se inscriben las luchas por el capital cultural en la sociedad. En concreto, el discurso sobre la música popular contemporánea, tal como se observa en las crónicas periodísticas de conciertos, se fundamenta en valores contrarios a los de la música clásica: la corporalidad, la emoción y lo femenino. Es así como las crónicas están llenas de metáforas que resaltan la irracionalidad y la energía. Si bien en principio tales valores fueron subversivos al enfrentarse en efecto a la cultura burguesa 
hegemónica, con el tiempo esta ha ido asimilando estilos como el jazz o el rock para desplazar a otros como el dance o el pop, asociados a lo comercial e inculto.

Palabras clave: rock, pop, crítica, discurso, cultura de masas.

\section{Descifrar la música}

Como afirma Simon Frith (1998: 4), el placer de la cultura pop está relacionado con el placer de hablar sobre ella, lo cual implica siempre algún tipo de valoración. Disciplinas como la filosofía, la musicología, la etnografía, la semiótica o, recientemente, los estudios culturales han aportado desde diferentes ángulos su visión sobre el significado que encierran las obras musicales, su historia, su relación con la sociedad y la cultura, la semejanza entre el código musical y el lenguaje humano, los discursos asociados con ella, las subculturas con las que se vincula, su carácter político o las identidades que forja.

Para Theodor W. Adorno, la música se asemeja al lenguaje humano en tanto en cuanto sucesión temporal de sonidos articulados, si bien no se le puede calificar como un código de signos, es decir, no es realmente un lenguaje. Aparte de la vinculación que el filósofo establece entre estética y verdad, merece la pena subrayar ciertas reflexiones relevantes: la crítica supone un modo de percepción de la música, sigue unas normas de apreciación distintas en cada época y es necesaria para experimentar plenamente esta práctica artística: «la crítica no penetra desde fuera en la experiencia estética, sino que le es inmanente» (Adorno, 1971: 449). Por lo tanto, se requiere una descodificación de la música para comprenderla y gozarla y, en este sentido, no existe otro medio de descifrar la música sino la propia lengua. Nótese que el pensador habla de descifrar y no de interpretar, actividad referida a la ejecución de la partitura; descifrar equivale a comprender la música, reflexionar sobre el código musical; en cambio, interpretar significa tocarla, imitarla, usar su código apropiadamente (Adorno, 2000: 27).

Sin embargo, más que reflexionar, la crítica otorga un significado a lo que es pura sintaxis; es decir, la música articula sonidos en función de determinadas técnicas de composición, reglas gramaticales o sintácticas -armonía, contrapunto-, que sin embargo carecen de semántica. Según explican Shepherd y Wicke (1997: 91), Kristeva afirma que la música no constituye un sistema de 
signos porque sus elementos constitutivos adolecen de falta de significado. Sin él, el único sentido que se puede atribuir a la música es subjetivo o cultural, es decir, los valores socioculturales de los que habla Adorno. El significado constituye, por lo tanto, el «resultado de una larga serie de efectos del discurso» (Gilbert y Pearson, 2003: 107), con lo cual son los medios, los críticos, los musicólogos, la industria discográfica, el público y los propios músicos quienes otorgan sentido a las obras a partir de la melodía, las letras, los gestos y otros elementos biogénicos de los que hablan Shepherd y Wicke. Este significado no es estrictamente subjetivo, individual o personal, ya que en él influye también el sentido que le otorga la sociedad, es decir, el imaginario social, la cultura (Adell, 2004: 149).

Trataré de indagar en el significado cultural de la música popular contemporánea mediante el análisis de una selección de las 184 crónicas musicales que el periodista Fernando Neira publicó en El País a lo largo de 2013. ${ }^{1}$ Las crónicas relatan espectáculos musicales, en su mayor parte de artistas y grupos rock y pop, que incluyen la valoración tanto de las canciones -música y letra-, como de la puesta en escena y la actuación. Una posible definición de crítica musical la ofrece Cantón García, que opone la valoración propia de este género al análisis que llevan a cabo los estudios musicales o la musicología:

1. Se pueden consultar en la edición digital del diario: «Iowa; capital, Woodstock» (1-2-2013), «Las leyes del contagio», (4-2-2013), «Del chiringuito a la etiqueta» (10-2-2013), «El turno de la catatonia» (20-2-2013), «Una paleta con todos los colores» (12-3-2013), «Lo estático y lo extático» (15-3-2013), «A un paso de la gloria bendita» (22-3-2013), «Gol de Alborán» (24-32013), «La casa por la ventana» (8-4-2013), «Ironía “gafapasta”» (10-4-2013), «Un revulsivo contra las fatalidades» (13-4-2013), «Sueños para la deconstrucción sonora» (17-4-2013), «Daneses adorables» (30-4-2013), «Las plantas sagradas que se desvanecen» (16-5-2013), «Melodrama llevadero» (19-5-2013), «Niño bonito para rato» (30-5-2013), «Movimientos ondulatorios» (4-6-2013), «La serena madurez de Los Secretos» (9-6-2013), «Confesiones de un chico sensible» (12-6-2013), «Epopeya ártica» (17-6-2013), «Gente triste que sufre y canta» (22-6-2013), «Audacia frente a sonrojo» (23-6-2013), «Barroquismo y magnificencia» (24-62013), «Mika, el arte de la canción para sonreír» (24-6-2013), «Aturdido en la encrucijada» (27-6-2013), «Mudémonos a California» (8-7-2013), «Melancolía electrificada» (8-7-2013), «Una diva seductora y cercana» (26-7-2013), «Joven airado y cantarín» (30-7-2013), «El cantor de todas las voces» (1-8-2013), «Música para el optimismo» (31-8-2013), «Solemnidad guitarrera» (4-9-2013), «El baile innegociable» (10-9-2013), «La pasión reconcentrada» (239-2013), «Los enamora a todos» (26-9-2013), «Más que un fenómeno juvenil» (27-9-2013), «El entusiasmo demediado» (8-11-2013), «El glorioso cuarentón» (10-11-2013), «DonostiaNashville» (11-11-2013), «Un superhéroe reinventado» (15-11-2013), «Los primates refinados» (16-11-2013), «Las letanías estremecedoras» (21-11-2013), «Camino de la excelencia» (26-112013), «Oscuridad controlada» (4-12-2013), «Antídoto navideño» (6-12-2013), «Danielito el zalamero» (6-12-2013), «El hombretón de las hechicerías» (10-12-2013) y «Con los párpados cerrados» $(16-12-2013)$. 
La crítica dedicada a la música se puede decir que consiste en el esclarecimiento, comprensión y valoración resultantes de un instintivo espectador informado que escucha atento una obra o una actuación musical, sin llegar a profundizar en los aspectos estructurales internos de ambas realidades, ya que tal misión está reservada a otro método de estudio como es el análisis, una de las disciplinas más importantes de la teoría general de la música. (Cantón García, 2004: 46)

Por lo tanto, la crítica musical, en forma de crónicas y reseñas, no constituye un estudio técnico o un tratado académico, ni siquiera es un género de divulgación musical. Por el contrario, se trata de un género que construye un discurso cultural acerca de la música y, en consecuencia, difunde valores, define estilos de vida, propone conductas y, en suma, crea identidades. Por decirlo así, los juicios sobre la interpretación o la técnica musical son secundarios, ya que el objetivo primordial de la crítica, al menos en las crónicas de Neira, es producir un discurso sobre la cultura popular contemporánea. La práctica ausencia de tecnicismos en los textos, en contraste con el empleo de un estilo retórico rico en metáforas, así lo certifica. Tal discurso surgió en la prensa anglosajona a partir de los años cincuenta del siglo Xx. En España, fueron publicaciones asociadas a la prensa underground las primeras que incorporaron a sus páginas reseñas, crónicas, reportajes y artículos sobre el pop y el rock, estilos que se consideraban contraculturales, es decir, que propugnaban un modo de vida alternativo al modelo burgués. Se trata de revistas como Musical, Popular 1, Disco-Express o Vibraciones, en las que la información musical coexistía con viñetas cómicas u otros temas como drogas, cine independiente, filosofía oriental, pensamiento posmarxista, literatura beat y otros intereses de la cultura hippie o, en general, como decimos, contracultural.

Para analizar el tipo de discurso de las crónicas musicales, comentaré, en primer lugar, su función sancionadora sobre gustos y, consiguientemente, la asignación de identidades que realiza; en segundo lugar, explicaré que el discurso sobre el pop y el rock es básicamente anticlasicista; finalmente, estableceré una serie de conclusiones que pondrán de relieve el carácter meramente esteticista de un lenguaje presuntamente revulsivo al haber sido asimilado al canon de la cultura «seria».

\section{Función social de la crítica de música}

Simon Frith (1996) subraya el vínculo, por un lado, entre música clásica y mente -seriedad-, y por otro, entre música popular y cuerpo-diversión-. En el 
fondo de tal relación se halla la dicotomía que el Romanticismo establece entre cultura y naturaleza, razón y sentimiento. En otras palabras, la cultura de masas crea obras carentes de mérito artístico; de hecho, la musicología, haciendo gala de su prejuicio cultural, ha ignorado el estudio de la música popular contemporánea y se ha ocupado tan solo de la clásica. Desde una óptica de género, la cultura de masas, además, está «asociada con la mujer, en tanto la cultura auténtica y real sigue siendo una prerrogativa de los hombres» (Huyssen, 2006: 94). En efecto, a finales del siglo XIX, las clases media y baja, la mujer, la naturaleza, el inconsciente, la sexualidad y la pérdida de la identidad se perciben como amenazas al orden racional burgués (Huyssen, 2006: 103). Sin embargo, con el paso del tiempo, se ha producido una asimilación de determinados estilos musicales como el jazz, el folk y el rock al canon cultural en una operación encaminada a neutralizar su potencial subversivo como obra de grupos que se oponen a la cultura burguesa.

El estatus cultural de la música, más que la literatura o el arte, ha sido fuente de polémica a lo largo de la historia. Tal como Gilbert y Pearson (2003) recuerdan, la música fue rechazada en bloque por lo que ellos denominan el «discurso metafísico», sostenido por algunos filósofos. En efecto, Kant -en sintonía con Platón-, argüía que, mientras la música solamente existiera para crear placer, más que como objeto de contemplación racional, no podría aspirar a la categoría de belleza. Además, a partir del siglo XIX, las actividades corporales se asocian con la laxitud moral y constituyen un obstáculo para la productividad económica de la élite social. Es entonces cuando la música penetra en el canon de alta cultura, pero únicamente la clásica por permanecer disociada de la materialidad del cuerpo, es decir, por ser un producto intelectual destinado al goce de la mente y articulada sobre patrones compositivos armónicos y ordenados. Más tarde, sin embargo, el posestructuralismo, especialmente a partir de la obra de la Escuela de Frankfurt, pondrá en duda las dicotomías mental/ físico y discursivo/no discursivo, con lo cual la diferencia problemática entre la emoción y el significado se esfuma, puesto que ambos se perciben como un todo indisociable. ${ }^{2}$ A partir de ese momento, la música popular, vinculada con el cuerpo y la emoción, iniciará un lento ascenso en el escalafón de la jerarquía cultural a raíz de la irrupción de las culturas juveniles, las subculturas y la con-

2. La importancia de la corporalidad se refleja muy claramente en las habituales descripciones de los elementos cinésicos de los espectáculos que se incluyen en las crónicas de Fernando Neira: «Durante la hora y media siguiente, Brett no parará de alzar los brazos, encaramarse a los monitores, soltar latigazos de cadera, descoyuntarse el cuello y demostrar su olímpico desprecio por la tecnología inalámbrica: los micrófonos «de verdad» sirven también como látigos implacables» («El glorioso cuarentón»). 
tracultura, fenómenos difíciles de distinguir debido a sus grandes similitudes, entre las que destaca su antagonismo con la cultura burguesa. ${ }^{3}$

De todos modos, ya desde prácticamente sus orígenes, al convertirse en una lucrativa industria de ocio, su potencial subversivo se atenuó y prácticamente ha desaparecido hoy en día - a excepción quizás del rap, aunque también sufre la misma presión mercantil e institucionalizadora. Poco a poco se aprecia cómo el jazz, el folk y el rock, sobre todo, van siendo absorbidos por el canon de la cultura seria, burguesa, legítima, aunque no con el mismo valor que todavía se asigna a la ópera, la sinfonía o el canto gregoriano. En efecto, estos estilos que surgieron de la cultura de masas se relacionan ahora con lo intelectual, lo auténtico, lo original, mientras que se margina a una categoría inferior a otras músicas como el dance o el pop. Todo ello da muestra de la constante reestructuración interna que se da en el campo cultural de la música. Jordi Busquet (2005: 135-136) critica la rigidez de la teoría del gusto de Bourdieu, para quien la cultura solo sirve para diferenciar unas clases sociales de otras sin tener en cuenta otra función primordial: la expresiva o comunicativa. En mi opinión, la explicación del sociólogo francés es todavía acertada, tal como se comprueba en las crónicas analizadas, si bien es cierto que tal función discriminadora coexiste con la expresiva. Busquet también alega que la explicación de Bourdieu está algo desfasada al olvidar la importancia de las modas, la globalización y la cultura de masas hoy en día. Sin embargo, aún siguen vigentes la alta cultura y el canon, aunque sujeto este último a una reestructuración permanente promovida por cuestiones de dominación y control, de preservación del orden social hegemónico; en concreto, como decíamos antes, determinados estilos como el jazz o el rock, originados en sectores marginales -la comunidad negra y la juventud, respectivamente- han sido absorbidos para eliminar su poder subversivo.

En efecto, en sus crónicas Neira ensalza el rock como un estilo más «elevado» que el pop, al que se tilda de «blando», «trivial», «superficial», «mercantil», «estandarizado», desprovisto del valor de obra «auténtica» y «seria»y asociado a la cultura juvenil (Keightley, 2001: 111). El pop se asocia al público adolescente, para el cual se componen canciones de temática sentimental, letras

3. Por ejemplo, Luis Racionero (1979: 24) confería a la música rock una dimensión espiritual que la mercantilización de la industria eliminó rápidamente. La música de los Beatles, los Rolling Stones y Bob Dylan poseía, para este escritor, un poder redentor que situaba al individuo en contacto con su energía vital reprimida. En sus memorias sobre la California hippie, incluso compara la actuación de los Rolling Stones en el festival de Altamont con un ritual en el que Mick Jagger actúa cual chamán capaz de elevar al éxtasis al público asistente (Racionero, 1988: 90). 
fáciles y melodías repetitivas. ${ }^{4}$ La distinción de grupos sociales en función del capital cultural se ejerce también mediante la definición del estilo del grupo o cantante: «pop romántico e intergeneracional» («Aturdido en la encrucijada»); «formación a medio camino entre Hollywood, el cabaret, la canción demodé, los clubes de jazz o las orquestas de baile cubanas» («Música para el optimismo»); «pop pastoral» («Con los párpados cerrados»). A veces, el crítico busca referencias a otros artistas para precisar el estilo y también describir el personaje. ${ }^{5}$ En otros casos también busca arquetipos sociales como «dandi engominado de voz profunda» o «crooner suburbial» («Los primates refinados»). Además, Neira recurre a otros referentes sociales, políticos o culturales para juzgar a los artistas: «El zurdo Eez Barzelay parece salido de algún lipdub de Nuevas Generaciones, pero hay bastante de irónico en el atuendo y, en general, en casi todo lo que pasa por las manos del líder de Clem Snide» («Ironía "gafapasta"»).

Como veíamos antes, las crónicas intentan dignificar la música popular contemporánea para legitimarla; en este sentido, es frecuente la alusión a otras esferas artísticas consolidadas como el arte, la literatura y el cine. ${ }^{6}$ De este modo, Neira describe a los artistas como «trovador» («Confesiones de un chico sensible») o «sirena nórdica» («Sueños para la deconstrucción sonora»); sus piezas constituyen una «Epopeya ártica», o bien se trata de un «rock poético» («Audacia frente a sonrojo») o de «épica solemne y guitarrera» («Solemnidad guitarrera»). Las referencias cinematográficas, como las literarias, no solo ensalzan la calidad del producto musical, sino que lo inscriben en un estilo de vida concreto, una subcultura, como en este caso la reputación de la que gozan las películas de Quentin Tarantino entre los fans indies: «los peculiarísimos Guadalupe Plata, un trío que se va con el blues por los cerros de Úbeda. Son

4. En el siguiente fragmento, Fernando Neira califica la música de Pablo Alborán de producto juvenil, es decir, comercial, melodramática y trillada: «Toda la noche recurre a esa poesía de mercadillo y musicasete («He pensado en ella toda la noche / en cada poro de su piel»), Me iré rima «ti» con «mí» y los futuros entre sí, y de Deshidratándome no se acordará casi nadie, puede que ni su autor, a la altura del cuarto o quinto disco. Pero a partir de Yo no lo sabía, un tema más elaborado e infinitamente menos predecible, se comprende que lo de este muchacho no será flor de unos pocos días» («Más que un fenómeno juvenil»).

5. «Ya en la segunda pieza, la novísima Barriers, aflora la fascinante fórmula magistral: Bowie con el traje de los Smiths, el glam, las guitarras cantarinas, la ambigüedad de aquella mítica portada que protagonizaban quién sabe si dos chicos, dos chicas o uno de cada cual» («El glorioso cuarentón»).

6. El cine, por cierto, al principio se consideraba un espectáculo de masas y, paralelamente a la música contemporánea, ha producido sus propias distinciones entre cine comercial, cine de autor, película de culto, cine independiente, cine de arte y ensayo, etc. 
marcianos, diferentes, fronterizos, algo tarantinos» («La casa por la ventana»).

El debate sobre la profesionalización de los críticos también ejemplifica el combate que se libra en el campo musical por la obtención del prestigio de aquellos que se dedican tanto a interpretar como a juzgar las obras. Estas luchas simbólicas, tal como las denomina Bourdieu, no se relacionan con el valor del producto, sino precisamente con la adjudicación del valor, una tarea de la que los críticos pretenden apropiarse de manera exclusiva rechazando el intrusismo de aficionados que emplean medios «no profesionales»-periódicos, revistas especializadas, libros-, además de los criterios comerciales que guían la información que los mismos medios ofrecen (Cantón García, 2004).

Huyssen (2006: 107) afirma que todavía está por determinar si el juego de valores que pone en liza el posmodernismo y que se reflejan claramente en la cultura y la música popular - la sexualidad, lo inconsciente, la corporalidad, lo femenino-suponen un nuevo canon o, en cambio, no son sino un estadio avanzado del modernismo - término propio de la cultura anglosajona que equivale a cultura burguesa en un sentido más amplio. En mi opinión, la transformación operada en el discurso en torno al rock-que se traduce en su legitimación como música seria, en su incorporación al canon-demuestra que los valores de la cultura de masas van penetrando poco a poco en la cultura legitimada, si bien están desprovistos del aura que envuelve a la música clásica y otras manifestaciones artísticas. Es así como se puede comprender la desaparición de la frontera entre cultura seria y cultura de masas que favorece el posmodernismo, según se explica a menudo en los estudios que se ocupan de ello. Aun así, Huyssen apunta que la crítica artística y literaria, en su mayoría, no ha abandonado los criterios propios del canon modernista -es decir, burgués-: la autonomía de la obra; su alejamiento de la vida cotidiana, fruto de un genio individual; su carácter autoconsciente y experimental; su capacidad para aportar saberes; su juego con el lenguaje y su desprecio hacia toda marca de subjetividad. Todo ello proporciona a la obra un carácter eterno y atemporal (Huyssen, 2006: 109). Por ello, concluye, cabe cuestionarse hasta qué punto el posmodernismo -que elimina las fronteras entre alta cultura y cultura de masas-propicia un cambio cultural efectivo (Huyssen, 2006: 113). En este sentido, comparto la idea de Huyssen de que sí existe una tentativa de fusionar la alta cultura con géneros y formas populares, aunque considero más relevante aún -como he señalado antes- la tarea de ennoblecer los valores propios de la cultura de masas que tiene que ver con fenómenos como el empuje que la globalización y la tecnología le proporciona, la consolidación de la clase media o el prestigio que han cobrado 
en los sectores intelectuales determinadas obras audiovisuales musicales por su calidad estética.

\section{Un discurso contra el clasicismo}

Roland Barthes, en su famoso ensayo titulado El grano de la voz (1978), insiste en que la música solo puede connotar, no denotar: tal connotación se expresa a través del lenguaje mediante el adjetivo: «viril», «solemne», «majestuoso», «modesto», «voluptuoso». Las indicaciones en italiano que a partir del Romanticismo utilizan los compositores -«allegro», «presto», «andante»- son también calificativos que dotan de significado a la partitura y orientan su ejecución. Para el semiólogo, el grano de la voz constituye la materialidad del cuerpo que canta. En efecto, basándose en los conceptos de fenotexto y genotexto, acuñados por Julia Kristeva, Barthes (1978: 182) define la fenocanción como el conjunto de todos aquellos rasgos que pertenecen a la estructura de la lengua en la que está escrita la canción, las reglas del género, el estilo interpretativo y el idiolecto del compositor, es decir, todo lo referente a la expresión, la representación y la comunicación; estas están constituidas por valores culturales, gustos, modas y comentarios críticos, asociados además con las convenciones estéticas y sociales de una época determinada. En cambio, la genocanción alude al volumen de la voz que canta o habla, es decir, al propio lenguaje, a la dicción, con sus pausas y sus respiraciones; el grano de la voz es, por lo tanto, tanto el timbre como sobre todo la lengua: «The grain is the body in the voice as it sings, the hand as it writes, the limb as it performs» (Barthes, 1978: 188). El discurso del rock y, por ende, de toda la música popular contemporánea reinstaurará de este modo la materialidad corporal al fenotexto y lo convertirá en un alegato contra el clasicismo que celebra los instintos, el movimiento, las emociones y los sentidos mediante un lenguaje altamente metafórico. ${ }^{7}$

Existe un léxico más neutro, literal o denotativo para describir la música que está relacionado con el sonido, es decir, la parte puramente material de la música, aunque ello no significa que las crónicas -un género periodístico interpretativo- se conviertan en informes imparciales o estudios desprovistos de toda traza de subjetividad. En efecto, si bien describen propiedades estrictamente sonoras, términos como «ruidoso», «chirriante», «murmullo», «baru-

7. De hecho, muchos nombres de festivales eluden utilizar el término «música», sustituido por «sonido» o, en inglés, «sound»-Primavera Sound, Arena Sound Festival, Sonorama, Visiones Sonoras-: sonido contra música, popular contra clásico. 
llo», «estallido», «rechinar», «susurro», «zumbido», «retumbar», «vibrante» o «zambombazo» adquieren matices plenamente valorativos al referirse a las canciones. Por otro lado, distinguen a la música popular contemporánea de la seria, ya que ponen de relieve cualidades censuradas en las obras clásicas, es decir, sonidos naturales -recordemos la distinción canónica entre naturaleza y arte o cultura- no sujetos a las normas de composición canónicas.

De todos modos, el material estrictamente sonoro es un elemento más en la valoración de la música que Fernando Neira expone en sus crónicas; de hecho, no es el más significativo. El discurso que este crítico elabora sobre la música gira en torno a dos ejes principales: el irracionalismo y la energía. Respecto al primero, destacan las alusiones al mundo animal, la magia y la brujería; por otra parte, la energía se asocia a metáforas sobre el fuego, la luz y el calor, además de otras sustancias orgánicas en las que abundan clichés como «inyección de adrenalina» o «producción colectiva de adrenalina» para describir los conciertos.

El irracionalismo se refleja, por un lado, en la utilización de vocablos relacionados con sonidos animales: «berrido», «marrullero», «aullar», «ronroneo», «dueño de una extraña voz de felino enfurruñado» («Solemnidad guitarrera»). De hecho, la animalización del artista ha proporcionado alguna colocación o cliché de empleo común en castellano como «animal escénico» («Movimientos ondulatorios»). Además de animalidad, la música se asocia a los sentidos; no tiene, de hecho, nada de extraño, si tenemos en cuenta que la música penetra a través del oído. Las crónicas, así, destacan la sensualidad; la referencia al tacto sirve, bien para juzgar negativamente las canciones - «sonido fofo e impersonal» («Más que un fenómeno juvenil»)-, bien para aprobarlas -«balada suave» («Los enamora a todos»); «el rock sedoso de Atlanta Rhythm Section» («Mudémonos a California»). El sentido del gusto también surge en las explicaciones: «Sus canciones rebuscan en el lugar donde se cruzan la dulce miel de Sam Cooke y el desgarro de Otis Redding» («Un revulsivo contra las fatalidades»); nótese, en este mismo ejemplo, el uso de la palabra «desgarro», que alude a la carnalidad, es decir, la corporalidad. Lo más habitual, sin embargo, es la utilización de la sinestesia para convertir los conciertos precisamente en todo lo contrario: un desconcierto que altere el orden tan caro al canon clásico. ${ }^{8}$

8. Algunos ejemplos son «mirada ácida» («Antídoto navideño»); «Ha tenido que ser este sexagenario quien escriba la canción más agria y encabronada sobre nuestra España perra» («Un superhéroe reinventado»); «sonido etéreo» («Barroquismo y magnificencia»); «serena sensualidad nórdica de The Cardigans» («Epopeya ártica»). 
Por otro lado, el rechazo de la razón se produce mediante la alusión a la magia, la religión y la brujería, actividades opuestas a la ciencia, con lo que una sesión de DJ se convierte en una «fascinante ceremonia de hechicería» («El hombretón de las hechicerías»); asimismo, términos como «abducción», «levitación», «apoteosis», «gloria», «espectral», «misterio» o «sortilegio» reflejan el carácter irracional de la música. ${ }^{9}$ De ese modo, los conciertos se convierten en celebraciones, rituales o ceremonias donde los fieles asistentes alcanzan el éxtasis a través de la música, como ocurre en las religiones africanas.

Finalmente, la dimensión irracional de la música se completa con la referencia al mundo de los sueños, con adjetivos como «pesadillesco» (sic), «hipnótico» u «onírico»:

El paralelismo es cierto, pero las opciones se van multiplicando en un maravilloso festín de sorpresas: el trompetista se vuelve mariachi en el delirio contemporáneo de «Step out for a while», el sinuoso crescendo de «The quiet crowd» imita el expresionismo del cine mudo alemán, la orgía ambiental de guitarra y bajo remite al éxtasis de Radiohead y el estratosférico «Adventures in your own backyard» equivale a un western onírico, la partitura de un Morricone empastillado («Una paleta con todos los colores»).

Obviamente, como se insinúa en la cita anterior, las drogas -una de las características más representativas de la contracultura de la que surge el rock en los años sesenta- también tiene cabida en las crónicas y acentúa, de hecho, lo irracional. ${ }^{10}$

La exaltación del irracionalismo está estrechamente vinculada con otro de los ejes sobre los que gravita el discurso sobre la música popular contemporánea en las crónicas de Neira: la energía. En sus crónicas periodísticas, la música es energía vital, lo cual se opone a la moderación, la mesura, el orden y la armonía del canon clásico. Euforia, desmadre, fuerza, plenitud, vigor, garra y otros términos similares dotan a la música de un efecto dionisíaco. De ahí

9. «[...] la voz de Devendra se multiplica como si en él habitaran abundantes espíritus; ora frágil y ultrasensible, ora opaca o de seductora profundidad. El hechizo prende con la irrupción de Igor Haefeli» («El cantor de todas las voces»).

10. «Una inmersión lisérgica sin necesidad de que el oyente abandone la abstemia» («Iowa; capital, Woodstock»); «Los prolegómenos no fueron menos espídicos» («Las leyes del contagio»); «En el universo cacofónico y anfetamínico del dúo canadiense no se estila la puntualidad ni el contacto visual con la parroquia» («El turno de la catatonia»); «Las dentelladas alucinógenas originales se desvanecían como humo» («Las plantas sagradas que se desvanecen»). 
proviene el ingrediente subversivo que la contracultura atribuyó al rock en sus orígenes. $^{11}$

En relación con la energía, existe un vasto campo semántico relativo a la luz, el calor y el fuego, metáforas vigorizantes que tienen que ver con la naturaleza. En concreto, «Un revulsivo contra las fatalidades» representa en su totalidad una alegoría del fuego: se trata de una crónica del concierto de James Hunter que emplea numerosos vocablos relacionados con este campo semántico: «flamígero disco de soul»; «vitalidad crepitante frente a la congoja»; «como si las notas le ardieran en las manos», «su flamante Minute by minute», «solos fulgurantes». ${ }^{12}$ Como contrapunto, también aparecen crónicas en las que Neira califica el estilo de un grupo en términos contrarios asociados a la oscuridad o el hielo. ${ }^{13}$

La energía que transmite la música penetra en el cuerpo y lo zarandea con toda suerte de movimientos espasmódicos, contorsiones y sacudidas que, por supuesto, escapan a toda norma domesticadora como en los ordenados y armónicos bailes aristocráticos -pero también los populares y tradicionales-:

No seamos cándidos: las casualidades nunca lo son del todo. Resulta que M\&S funcionan sobre el escenario como locomotoras. Son enérgicos, trepidantes, imparables, espasmódicos. Winston Marshall se contonea con su

11. «La suma tiene efectos sencillamente euforizantes» («Epopeya ártica»); «arrebatos rítmicos» («Niño bonito para rato»); «Sus canciones equivalen a inyectables de energía en vena. Son redondas, pletóricas, vigorizantes y, en su género, impecables. Irreprochables. Perfectas» («Mika, el arte de la canción para sonreír»); «Es pop experimental y de partitura, con una pequeña sección de metales que añade barroquismo, sutiles atisbos electrónicos, compases quebrados, voces de perplejidad onírica y ni rastro de guitarras» («Barroquismo y magnificencia»); «catarsis más ruidista» («La pasión reconcentrada»); «conciben cada estribillo como un clímax de notas agudas que debe ser saludado brazos en alto y con la euforia desencajándonos las pupilas» («Danielito el zalamero»).

12. Otros ejemplos son: «la volcánica Malú» («Gol de Alborán»); «esa inmensa fogata nocturna en que se convierte Colours» («Las plantas sagradas que se desvanecen»); «el fulgor acústico de The Lumineers» («Epopeya ártica»); «la inaugural Buena chica suena más eléctrica y chisporroteante que nunca» («La serena madurez de Los Secretos»); «arpegios cristalinos» («Melancolía electrificada»); «prístinas armonías» («Joven airado y cantarín»); «Por mucho que Cactus, el favorito de Bowie, abriese la velada, la teórica bomba de neutrones se quedó en fogueo de trámite» («El entusiasmo demediado»); «la crepuscular y emocionantísima England» («Las letanías estremecedoras»); «Glasvegas gestionan una oscuridad controlada, una negritud dentro de un orden, tenebrosos» («Oscuridad controlada»); «cálidos arpegios africanizantes» («Camino de la excelencia»).

13. Algunos ejemplos son: «belleza polar» («Lo estático y lo extático»); «unos teclados gélidos» («Daneses adorables»). La alusión a fenómenos atmosféricos también asocia la música a la naturaleza y la energía: «chaparrones eléctricos» («La casa por la ventana»); «tormentas de electricidad guitarrera» («Oscuridad controlada»). 
banjo como si fuese a arrancarle el mástil, Ted Dwane se juega la luxación de tanto cabecear, en éxtasis, con el contrabajo entre los dedos; Ben Lovett aporrea el teclado y mira de reojo a Marcus Mumford, el hombre que canta, patea el bombo y maltrata la acústica («A un paso de la gloria bendita»).

La exaltación del cuerpo - reincorporado a la música tras el menosprecio que las convenciones clásicas le dedican a partir del siglo XVIII- se manifiesta también en la presencia de metáforas que aluden a la intensidad del sonido -la energía- y que incluyen términos como «músculo», «garra», «carnalidad»o «cuerpo». ${ }^{14}$

\section{Conclusiones: un discurso estetizante}

Tras años de desarrollo de la música popular contemporánea, la lucha simbólica de los agentes que cohabitan en tal campo ha generado nuevos conflictos entre sus diferentes estilos, aunque los criterios esgrimidos, pese a funcionar también como reguladores del gusto y de la distinción, son básicamente los relativos a la comercialidad. Las crónicas analizadas constituyen, así pues, un discurso sancionador que regula los usos y las identidades que se construyen dentro del campo cultural de la música popular, de modo muy similar a la dinámica que se establece en el campo literario. Si bien la música clásica se consideraba un signo de distinción de la clase hegemónica como alta cultura, en cambio ahora la «democratización» de la cultura, el desarrollo de una tradición propia de los estilos populares, el auge enorme de la cultura de masas y la extensión de la clase media, ha facilitado la creación de nuevos valores de «refinamiento» que sirven para diferenciar grupos en función del acceso que tienen al capital cultural. Así, las clases medias, dado que no pueden apoderarse de los mismos valores que caracterizan a la cultura asociada a la clase dominante, pretenden legitimarse potenciando una serie de valores, prácticas y estilos de vida entre los que figura en un lugar preferente la música -el rock y el folk, a los que se podría añadir también, por ejemplo, la canción «de au-

14. Ejemplos de ello son: «a veces aún le falta hacer sangre, aventurarse más al desgarro de $M i$ rutina preferida» («Melodrama llevadero»); «Su folk-pop elegante va ganando en músculo, carne y hasta mala baba (Catastrophe of love), con algún tema, en particular «Oh I oh oh I', que araña como cuando Tori Amos tenía bien afiladas las uñas» («Gente triste que sufre y canta»); «un Temptation carnal y canalla» («Una diva seductora y cercana»); «Tampoco ayuda que el sonido, en los primeros momentos, se note timorato y escaso de cuerpo» («DonostiaNashville»). 
tor» o el indie. La música popular «comercial»-determinados estilos pop, el dance-son, en este sentido, sinónimo de mediocridad intelectual, escaso nivel cultural, adolescencia, estética hortera o extracción social inferior. ${ }^{15}$ Por lo tanto, la música popular, en bloque, ya no sirve para distinguir identidades sociales; actualmente, en el escalafón de estilos musicales, la posición más baja está ocupada por las músicas que utilizan medios electrónicos, temas sentimentales plagados de clichés, bailes y melodías convencionales.

En este artículo hemos visto cómo el canon clásico rechaza la música popular contemporánea asociándola a valores contrarios a aquellos que la legitiman; en efecto, la emoción, los sentidos, la corporalidad o el irracionalismo se oponen a la supremacía del intelecto, la mente o la razón. En las crónicas de Fernando Neira, lo irracional se expresa mediante metáforas relacionadas con la animalización, la magia, la brujería, la religión, los sueños y las drogas. Esta liberación de los instintos crea una energía que provoca el máximo goce de los sentidos y que se representa mediante el uso de un rico arsenal de metáforas relativas a la luz, el calor y el fuego, es decir, elementos naturales. Así pues, el discurso sobre la música popular contemporánea se vincula con la materia, el cuerpo, la sensualidad, la naturaleza y el vitalismo. Sin embargo, tal como indica Abad (2002: 152), la conversión del arte en ocio y las interpretaciones académicas han generado una lectura esteticista del rock, frenando y eliminando la capacidad de acción y de crítica. La prensa, y concretamente las crónicas y las reseñas musicales, también contribuyen a la estetización de un discurso aparentemente revolucionario al atacar las convenciones sociales y culturales de la burguesía. Efectivamente, el discurso irracional y eufórico elaborado sobre la música popular no propugna en absoluto un cambio social, político y cultural que vaya más allá de la consolidación de la clase media, o la pequeña burguesía - para utilizar un término más tradicional-, dotándola de prestigio y autoridad. Las crónicas se revelan, en este sentido, como un relato colorista que propone el estilo como rechazo (Abad, 2002: 126), aun cuando este carácter antisocial, una vez institucionalizado, deviene un mero signo de distinción propio del esnob y del dandy, pura retórica desprovista de crítica social: el estilo del radical chic, por usar el irónico término que popularizó Tom Wolfe en alusión a la izquierda culta y liberal de los años sesenta.

15. En este sentido, se aprecia cómo las reglas de funcionamiento del campo de la música son muy similares a las de la literatura, ya que el desinterés por el dinero es la fuente más importante de capital -legitimidad y prestigio-. 


\section{Referencias bibliográficas}

Abad, L. A. (2002): Rock contra cultura, Madrid, Biblioteca Nueva.

AdELL, J. E. (2004): «La música popular contemporánea y la construcción de sentido: Más allá de la sociología y la musicología» en RuesGa, J. (ed.) (2004): Intersecciones. La música en la era electro-digital, Artefacto, Sevilla, 137-150.

Adorno, T. W. (1971): Teoría estética, Madrid, Taurus.

- (2000): Sobre la música, Barcelona, Paidós.

BARTHES, R. (1978): «The grain of the voice», Image, music, text, Nueva York, Farrar, Straus and Giroux.

Bourdieu, P. (1998): La distinción. Criterios y bases sociales del gusto, Madrid, Taurus.

BusQuet, J. (2005): Els escenaris de la cultura, Barcelona, Ara Llibres.

Cantón García, J. A. (2004): «Prensa y música: divulgación y crítica», Comunicar, 23: 43-47.

Frith, S. (1996): Performing Rites: On the Value of Popular Music, Cambridge, Harvard UP.

Gilbert, J.; E. Pearson (2003): Cultura y políticas de la música dance, Barcelona, Paidós.

Keightley, K. (2001): «Reconsidering rock» en Frith, S.; W. STRaW; J. STREeT (eds.) (2001): The Cambridge Companion to Pop and Rock, Cambridge: Cambridge UP, 109-142.

Huyssen, A. (2006): «La cultura de masas como mujer: lo otro del modernismo», Después de la gran división. Modernismo, cultura de masas, posmodernismo, Buenos Aires, Adriana Hidalgo Editora, 89-120.

RACIONERo, L. (1979): De qué iban los 60: mitos y ritos, Madrid, Ediciones de La Piqueta.

- (1988): Memòries de Califòrnia, Barcelona, Edicions 62.

ShePherd, J.; P. WiCKe (1997): Music and Cultural Theory, Cambridge, Polity.

Wolfe, T. (2002): Radical Chic \& Mau-mauing the Flak Catchers, Londres, Picador. 